\title{
Pharmacological treatment for attention deficit hyperactivity disorder: functional outcomes in children and adolescents from non-Western countries
}

\author{
Murat Altin, ${ }^{1}$ Ahmed A El-Shafei, ${ }^{2}$ Maria Yu, ${ }^{3}$ Durisala Desaiah, ${ }^{4}$ Tamas Treuer, ${ }^{5}$ Nikolay Zavadenko, ${ }^{6}$ Hong Yun Gao ${ }^{7}$ \\ 'Eli Lilly Neuroscience, Eli Lilly \& Company Turkey, Lilly Ilaç Ticaret Ltd. Şti. Kuşbakişi Caddesi, Rainbow Plaza No:4 Kat:3,34662; Altunizade, Istanbul, Turkey; \\ 2Eli Lilly, 1229 El Sheikh Aly Gad El Haq St., Floor 6 Sheraton Bldgs, Heliopolis, Cairo, Egypt; ${ }^{3}$ Eli Lilly Canada, 3650 Danforth Ave, Toronto, Ontario, Canada; \\ ${ }^{4}$ Lilly Research Laboratories, Lilly Corporate Center, Indianapolis, IN; ${ }^{5}$ Neuroscience Research, Eli Lilly and Company, 1075 Budapest, Madách u. 13-14, Hungary; \\ ${ }^{6}$ Dept. of Neurology, Neurosurgery and Medical Genetics of Pediatric Faculty, Russian State Medical University, Ostrovityanova Str. 1, Moscow, Russian Federation; \\ 'Dept. of Psychological Medicine, Children's Hospital of Fudan University, 399 Wanyuan Lu, Shanghai, China
}

\begin{abstract}
Objective: Functional outcomes were measured over a 12-month period in children and adolescents with attention deficit hyperactivity disorder (ADHD) after they received monotherapy.

Design: Prospective, observational, noninterventional study.

Setting: Conducted in six non-Western countries.

Participants: Outpatients 6 to 17 years of age with a verified diagnosis of ADHD in accordance with the Diagnostic and Statistical Manual, Fourth Edition, Text Revision (DSM-IV-TR), together with their physicians, decided to initiate or switch treatment for ADHD. Patients were prescribed pharmacological monotherapy: methylphenidate ( $n=221)$, nootropic agents $(n=91)$, or atomoxetine $(n=234)$.
\end{abstract}

Measurements: Patients were followed for changes in their functional status and quality of life, which were assessed with the Child Health and IIIness Profile-Child Edition (CHIPCE) Achievement domain.

Results: At the end of the study, a mean improvement on the CHIP-CE Achievement domain score was observed for all countries and therapies except in Taiwan, where patients received atomoxetine, and in Lebanon, where patients received methylphenidate. No patient experienced a serious adverse event during the study. Four patients discontinued due to a treatment-emergent adverse event

Conclusion: After 12 months of treatment, clinical and functional outcomes were improved in children and adolescents from non-Western countries who initiated and remained on their prescribed pharmacological monotherapy.

Keywords: atomoxetine, attention deficit hyperactivity disorder, adolescent, child, adverse drug events, treatment outcome, nootropic agents, central nervous system stimulants.

Citation

Provenance

Dates

Copyright

Correspondence address

Email address

Competing interests

Abbreviations

Trial Registration Number
Altin M, El-Shafei AA, Yu M, Desaiah D, Treuer T, Zavadenko NN, Gao HY. Pharmacological treatment for attention deficit hyperactivity disorder: functional outcomes in children and adolescents. Drugs in Context 2013; 212260. doi: 10.7573/dic.212260

Submitted; externally peer reviewed

Submitted: 8 May 2013; Accepted, subject to peer review: 10 May 2013; Published: 13 September 2013

(c) 2013 Altin M, El-Shafei AA, Yu M, Desaiah D, Treuer T, Zavadenko NN, Gao HY. This is an open-access article distributed under the terms of the Creative Commons Attribution License (CC-BY-NC-ND 3.0) which allows unrestricted sharing, copying and distribution for personal use provided it is properly attributed. No other uses without permission.

Murat Altin, MD; Lilly Turkey; Lilly Illaç Tic. Ltd. Şti.Kuşbakişi Caddesi, Rainbow Plaza No:4 Kat:3,34662; Altunizade, Istanbul, Turkey altin_murat@lilly.com

Murat Altin, Ahmed El-Shafei, Maria Yu, Durisala Desaiah, and Tamas Treuer are full-time employees and minor stakeholders of Eli Lilly and Company. Nikolay Zavadenko has received research support and speaker honoraria from Eli Lilly Vostok, Sanofi-Aventis Russia, and PIK-Pharma Russia and has served on advisory boards for Eli Lilly Vostok. Hong Yun Gao has received research support from Eli Lilly and Company for this work.

ADHD, attention deficit hyperactivity disorder; AE, adverse event; CHIP-CE, Child Health and IIIness Profile-Child Edition; CGI-ADHD-S, Clinical Global Impressions-ADHD-Severity; Cl, confidence interval; CSI-4, Child Symptom Inventory-4 Parent Checklist; ERB, ethical review board; MMRM, mixed-effects model with repeated measures; SAE, serious adverse event; SD, standard deviation; SNRI, serotoninnorepinephrine reuptake inhibitors; TEAE, treatment-emergent adverse event; UAE, United Arab Emirates.

Observational study, therefore no registration.

Drugs in Context - The journal of interventions in clinical practice

This full text PDF downloaded from www.drugsincontext.com

Drugs in Context 2013; 212260. ISSN 1740-4398

Copyright ( 2013 Altin M, El-Shafei AA, Yu M, Desaiah D, Treuer T, Zavadenko NN, Gao HY. Distributed under the terms of the Creative Commons Attribution License CC-BY-NC-ND 3.0. No other uses without permission. 


\section{Introduction}

Attention deficit hyperactivity disorder (ADHD) is a central nervous system disorder that has its onset in childhood and is estimated to occur in 3-8\% of children [1,2]. The disorder does not appear to be an acute or episodic illness, but rather a genetic or developmental alteration in particular cognitive or behavioral pathways and/or their regulation that is expressed as chronic hyperactivity-impulsivity and/or difficulties in sustaining attention $[3,4]$. ADHD often results in a number of functional impairments including academic difficulties [5,6] and social skills deficits [7-9]. Functional disability, primarily including academic performance, is a major concern for most parents who have children with ADHD.

There is a range of approved and unapproved pharmacological agents used in general medical practice for ADHD treatment in pediatric patients worldwide. These include psychostimulants, selective serotonin reuptake inhibitors and serotonin-norepinephrine reuptake inhibitors (SNRIs), other noradrenergic agents, antidepressants, antipsychotics, and nootropic agents [10]. Current therapeutic approaches to ADHD treatment vary significantly on a geographic basis. In many countries and regions, especially in non-Western countries, approaches to treatment and prescription patterns are poorly defined [11].

This study was designed to describe functional outcomes and their correlation to clinical outcomes and treatment tolerability over a 12-month period in children and adolescents from nonWestern countries with ADHD, who switch, initiate, or reinitiate treatment with a single pharmacological agent, namely the SNRI atomoxetine, the stimulant methylphenidate, or a nootropic agent.

Russia as well as some Asian, Middle Eastern, and Northern African countries, amongst others, are less studied in terms of typical patterns of ADHD pharmacological treatment. In Russia, where stimulant medications do not have marketing approval, ADHD is treated with a range of drugs; mainly nootropic agents, such as piracetam, are used due to their actions as cognitive enhancers [12,13]. However, in most other parts of the world, especially in non-Western countries, stimulant medications are likely to be the preferred form of drug treatment for ADHD $[11,14]$. Atomoxetine is a nonstimulant, centrally acting, SNRI with little or no affinity for other transporters or neurotransmitter receptors [15]. Atomoxetine has been demonstrated to be an efficacious, well-tolerated treatment in children and adolescents diagnosed with ADHD in several clinical trials [16-18].

Functional outcomes of ADHD pharmacologic treatments may vary in different regions of the world, but there is a critical lack of knowledge regarding the treatment of ADHD in many non-Western countries. The efficacy and tolerability of drugs developed in the Western hemisphere has not been well studied in different ethnic and cultural settings in other parts of the world, particularly in relation to the level of functional impairment and quality of life [11]. Indeed, the broader efficacy and tolerability of ADHD therapies remain an area of current research, even in Western countries [2].

The primary measure of treatment effectiveness for ADHD in children and adolescents in this study was improvement of parent-rated functional outcomes, especially those related to the child's ability to meet his/her parent's expectations in social ac- tivities (e.g., at school, with peers). The Child Health and Illness Profile-Child Edition (CHIP-CE) Achievement domain was used for this evaluation due to its proven validity and accuracy in large-scale trials [19-21].

\section{Methods}

\section{Study design and patients}

This was a noncomparative, prospective, observational, noninterventional study to describe functional outcomes/quality of life in children and adolescents with ADHD who were initiating therapy with a single pharmacological agent in non-Western countries. Enrollment was initiated on 8 January 2009, with the last patient visit on 2 March 2011. Outpatients 6 to 17 years of age were recruited at 28 study centers in the Russian Federation, China, Taiwan, Egypt, United Arab Emirates (UAE), and Lebanon. The patients had verified diagnosis of ADHD in accordance with the Diagnostic and Statistical Manual, Fourth Edition, Text Revision (DSM-IV-TR) and, together with their physicians, decided to initiate or switch treatment for ADHD. Patients were to have attended school for at least the previous 4 weeks and were to continue to attend classes for at least 4 weeks before the summer vacation period. Eligible patients were either initiating or switching treatment for $\mathrm{ADHD}$ and only patients initiating monotherapy with methylphenidate, nootropic agents, or atomoxetine for the treatment of ADHD could be enrolled in the study. Eligible patients were without significant or unstable mental or general medical comorbidities and could not be involved in a concurrent controlled clinical trial.

For both the atomoxetine and methylphenidate, it was assumed that an improvement of 7 in CHIP-CE Achievement domain score would be observed at 12 months with a standard deviation (SD) of 9. With this, a sample size of 80 was needed to obtain a $95 \%$ confidence interval (CI) of width 4 . For nootropic agents, a sample size of 35 was needed to provide $95 \%$ CI of width 6, assuming an improvement of $5(\mathrm{SD}=9)$. To account for drop-outs and switching, enrollment was set at 220, 220, and 100 for atomoxetine, methylphenidate, and nootropic agent arms, respectively.

Due to a relatively low rate of use of atomoxetine [11], possibly less than $10 \%$ in most countries, recruiting participants at a natural rate would accrue approximately 2000 stimulant group patients before achieving our required goal of 220 atomoxetine group patients. So, to achieve the required sample size, a strategy of oversampling of atomoxetine patients was proposed. This involved recruiting atomoxetine patients throughout the 6-month enrollment window; however, patients taking stimulants would only be invited to participate at regulated intervals (or windows) over the 6-month period. The relatively small sample size (220 atomoxetine patients) and 44 potential sites combined with the extended 6-month enrollment period were designed to enable recruitment of atomoxetine in a natural manner despite its lower relative use.

The study duration was 12 months to allow time to observe changes in the primary endpoint over the course of a full school year or equivalent. Patients who discontinued their initially prescribed monotherapy treatment were to be followed for the 
12-month study duration because monotherapy treatment discontinuation was not a reason for study discontinuation. There were six scheduled assessment points during the study. Visit 1 (study entry) was at the time of pharmacological agent prescription for ADHD treatment. The post-study entry assessments were as follows: Visit 2 (Month 1), Visit 3 (Month 3), Visit 4 (Month 6), Visit 5 (Month 9), and Visit 6 (Month 12).

As this was an observational study and did not impose any form of intervention, along with the assent of the patients, the parents/guardians of patients provided written authorization for the use and disclosure of their personal health information as described in the study Consent to Release Information. This consent covered the collection and release of data regarding treatment and its outcomes for the duration of the study. The confidential nature of patient information was maintained, and all local regulations were followed.

This study was submitted to an ethical review board (ERB) for approval whenever required by local law. In addition, regardless of local law, the study was submitted to at least one ERB per country for review and to confirm that the study was considered noninterventional in that country. This study was conducted in accordance with the ethical principles that have their origin in the Declaration of Helsinki and that are consistent with good clinical practices and applicable laws and regulations of the country or countries where the study was conducted, as appropriate.

\section{Effectiveness and safety measures}

The primary outcome measure was the change in CHIP-CE Achievement domain score from the baseline to endpoint. The CHIP-CE is a parent-completed instrument that measures overall quality of life and other areas to assess mental health, self-esteem, general behavior, and involvement with family and peers. The Achievement domain (1 of 5 CHIP-CE domains) is a 10-item scale that measures the extent to which a child meets expectations for role performance in school and with peers (subdomains: Academic performance and Peer relations) $[22,23]$. The validity and reliability of CHIP-CE has been confirmed in children with ADHD across the United States [22,23], and Europe [21].

Secondary outcome measures included the other four domains of the CHIP-CE: Satisfaction, Comfort, Resilience, and Risk Avoidance. The clinician-rated, 7-point, single-item Clinical Global Impressions-ADHD-Severity (CGI-ADHD-S) scale was used to assess the severity of ADHD symptoms [24]. A comprehensive assessment of child psychopathology in various mental disorders was carried out using the 97-item Child Symptom Inventory-4 Parent Checklist (CSI-4) [25]. Comorbidities were evaluated using the CSI-4 (Categories B-J) and the Adolescent Symptom Inventory-4 Parent Checklist [26] Categories L (bipolar disorder) and $\mathrm{O}$ (substance abuse).

Safety measures included serious adverse events (SAEs), treatment-emergent adverse events (TEAEs), and adverse events (AEs) that led to study discontinuation.

\section{Statistical analyses}

The primary analysis used an "on-drug" analysis population. Patients who discontinued their originally prescribed pharmaco- monotherapy were excluded from the point of discontinuation. For those patients who were lost to follow-up or who dropped out from the study, the analyses included all data up to the point of the last data collection.

This was an observational study looking at treatment patterns specifically for each participating non-Western country. The trial was not designed to compare treatment groups.

Descriptive statistics were used to summarize patient characteristics at study entry for all enrolled patients. Demographic data collected included age, gender, race, weight at study entry, and previous ADHD treatment. The primary endpoint, change from baseline of CHIP-CE Achievement domain score, was analyzed by country and treatment using a likelihood-based, mixedeffects model with repeated measures (MMRM). Adjustment for ADHD severity at study entry was prespecified; however, the model failed to converge with this term so it was removed from the final model. A similar analysis was performed for change in CGI-ADHD-S and CSI-4 from study entry to final visit. To standardize CHIP-CE and CSI-4 symptom severity scores, they were compared to normative samples. Higher CHIP-CE scores indicated better health, and lower CSI-4 scores indicated symptom severity.

Correlation of the change in ADHD severity with change in functional outcomes was calculated with the Pearson correlation statistic with associated 95\% CI.

Safety analyses were conducted on the full analysis set population. This included any patient with at least one visit post-study entry. Incidence rates of TEAEs were summarized descriptively by preferred term and system organ class.

\section{Results}

\section{Patient disposition}

At study entry, a total of 546 patients were enrolled; 234 patients were prescribed atomoxetine, 221 patients were prescribed methylphenidate, and 91 patients were prescribed nootropic agents. The proportion of patients who completed the 12-month study (through Visit 6) was 62.4\% (atomoxetine, $\mathrm{n}=146$ ), $60.2 \%$ (methylphenidate, $\mathrm{n}=133$ ), and $84.6 \%$ (nootropic agents, $\mathrm{n}=77$ ).

\section{Treatment adherence}

At final visit (Visit 6), 113 of 219 (51.6\%) patients were still receiving their originally prescribed atomoxetine treatment, 102 of $204(50 \%)$ patients were still receiving their originally prescribed methylphenidate treatment, and 67 of 91 (73.6\%) patients were still receiving their originally prescribed nootropic agent treatment. Changes in treatment regimens during the 12-month study are summarized by country and treatment in Table 1 .

The majority of patients, with the exception of those in China, did not discontinue their original monotherapy during the study. In China, $58.0 \%$ of patients receiving atomoxetine and $49.3 \%$ of patients receiving methylphenidate discontinued their original monotherapy treatment during the study and did not start a new treatment (Table 1). Additionally, a high proportion of patients from Taiwan did not complete the study $(90.9 \%$ atomoxetine patients; $66.7 \%$ methylphenidate patients). A patient's 
discontinuation from original monotherapy or switching was not obtained after the patient discontinued the study.

Reasons for monotherapy discontinuation are summarized by country and treatment in Table 2 . Nearly all patients who discontinued the study prior to the final visit were either lost to follow-up or discontinued due to parent/caregiver decision (47.5\% atomoxetine patients; $57.7 \%$ methylphenidate patients; $25.0 \%$ nootropic agent patients). China had the highest percentage of discontinuations $58.0 \%$ of atomoxetine patients and $49.3 \%$ of methylphenidate patients). In patients from China, the most common reasons for discontinuation were caregiver decision $(\mathrm{n}=12)$ and lack of effect $(\mathrm{n}=11)$ with atomoxetine therapy and caregiver decision $(\mathrm{n}=24)$ with methylphenidate therapy.

\section{Demographics}

Demographic characteristics are summarized by treatment group in Table 3. The mean age (SD) of patients enrolled in this study was 9.6 (2.8) years in the atomoxetine group, 9.9 (2.7) years in the methylphenidate group, and 9.4 (2.5) years in the nootropic agent group. With three exceptions, all patients were either White or Asian. The majority of patients were male (atomoxetine, $88.0 \%$; methylphenidate, $81.4 \%$; nootropic agents, $76.9 \%$ ).

A score of 43 or below on a CHIP-CE domain indicates poor health in that domain while a score of 57 or higher indicates excellent health [27]. At study entry, low values for the CHIPCE Achievement, Satisfaction, and Risk Avoidance domains were observed, indicating an impaired quality of life in this group of patients (Table 3). In all three treatment groups, the mean Comfort domain standardized scores (mean [SD]) at study entry approached or were within the normal range (atomoxetine, 41.8 [12.2]; methylphenidate, 44.5 [11.7]; nootropic agents, 48.5 [10.2]). Mean Resilience domain standardized scores were within the normal range for the nootropic agent treatment group (43.4 [10.3]), but reflected impairments in the atomoxetine (30.0 [13.4]) and methylphenidate groups (27.6 [13.5]). CGIADHD-S scores indicated that a majority of patients who were prescribed atomoxetine or methylphenidate were moderately to markedly ill, while a majority of those prescribed nootropic agents were mildly to moderately ill (Table 3 ).

The proportion of patients meeting physician-rated CSI- 4 screening cut-off scores for ADHD-combined, hyperactive-impulsive, and inattentive subtypes are shown in Table 4. Overall, ADHD-inattentive was the most common subtype reported at baseline for all three treatment groups across countries. A much lower percentage of patients met screening cut-off scores for combined $(20.6 \%$ vs $43.0 \%$ overall), hyperactive-impulsive $(32.4 \%$ vs $51.5 \%$ overall), and inattentive ( $37.1 \%$ vs $63.3 \%$ overall) subtypes in Taiwan for the atomoxetine group. The most common psychiatric comorbidities reported at baseline were specific phobia (8.7-66.7\%), vocal tics (7.4-60.0\%), and oppositional defiant disorder (21.7-50.0\%). A high proportion of atomoxetinetreated patients from Taiwan reported meeting screening cut-off scores for obsessions, motor tics, and vocal tics $(51.4 \%, 57.1 \%$, and $60.0 \%$, respectively) (Table 4), compared to the overall proportion of patients meeting cut-off scores $(34.8 \%, 34.8 \%$, and $37.0 \%$, respectively).

\section{Functional outcomes}

The CHIP-CE Achievement domain mean standardized scores at study entry and final visit are summarized by country and treatment in Figure 1a. Data collected after patients discontinued the original monotherapy medication were excluded from the analyses. The mean change from baseline to endpoint of the Achievement domain score is shown by country in Table 5 . At the end of the study, a mean improvement (increase) on the CHIP-CE Achievement domain score was observed for patients in all countries and on all therapies except patients in Taiwan who received atomoxetine $(-4.2,95 \% \mathrm{CI}[-9.8,1.3])$ and patients in Lebanon who received methylphenidate $(2.0,95 \%$ CI $[-1.9,6.0])$.

The CGI-ADHD-S scores at study entry and final visit are summarized by country and treatment in Figure 1b. For patients who remained on their originally prescribed treatment, a mean improvement (decrease) on CGI-ADHD-S score was observed at the end of the study for all countries and therapies (Table 5). For patients who remained on their originally prescribed treatment, a mean improvement on the CSI-4 ADHD combined-type symptom severity score was observed at the end of the study for all countries and therapies except patients in Taiwan who received atomoxetine $(2.2,95 \%$ CI $[-4.8,9.2])$.

Correlation values between the CGI-ADHD-S and CHIP$\mathrm{CE}$, and between the CSI- 4 and CHIP-CE are summarized in Table 6. As shown in Table 6, CHIP-CE Achievement and Risk Avoidance domains are negatively correlated with CGI-ADHD$\mathrm{S}$ and CSI-4 scores for atomoxetine and MPH.

\section{Safety measures}

No patient experienced an SAE during the study. Four patients discontinued due to a TEAE. In the atomoxetine group, one patient discontinued due to a TEAE of insomnia. In the methylphenidate group, the TEAEs that led to discontinuation of three patients included headache, anxiety, and depressed mood.

In patients from China, the incidence of TEAEs was $26.0 \%$ $(\mathrm{n}=13)$ in patients who took atomoxetine $(\mathrm{N}=50)$ and $21.1 \%$ $(\mathrm{n}=15)$ in patients who took methylphenidate $(\mathrm{N}=71)$. With both treatments, the most common TEAE was decreased appetite (16.0\% atomoxetine; $12.7 \%$ methylphenidate). Insomnia occurred in $7.0 \%$ of patients from China treated with methylphenidate and none treated with atomoxetine. All other TEAEs occurred in no more than one patient per treatment. In Taiwan and UAE, one patient from each country reported a TEAE (1 atomoxetine UAE [insomnia, dizziness, headache, and abdominal discomfort]; 1 methylphenidate Taiwan [rhinitis allergic]).

In Egypt, the incidence of TEAEs was $0 \%$ among patients who took atomoxetine $(\mathrm{N}=42)$ and $5.7 \%$ (2 patients) among those treated with methylphenidate $(\mathrm{N}=35)$. Each event in the methylphenidate group occurred only in one patient. The incidence of TEAEs in patients from Lebanon was $8.7 \%(\mathrm{n}=2)$ in patients who took atomoxetine $(\mathrm{N}=23)$ and $11.1 \%(\mathrm{n}=4)$ in patients who took methylphenidate $(\mathrm{N}=36)$. In patients treated with methylphenidate, the most common TEAE was headache $(8.3 \%$ [3 patients]). All other TEAEs occurred in no more than one patient per treatment group. The incidence of TEAEs in Russian patients was $11.8 \%(\mathrm{n}=6)$ in patients who took 

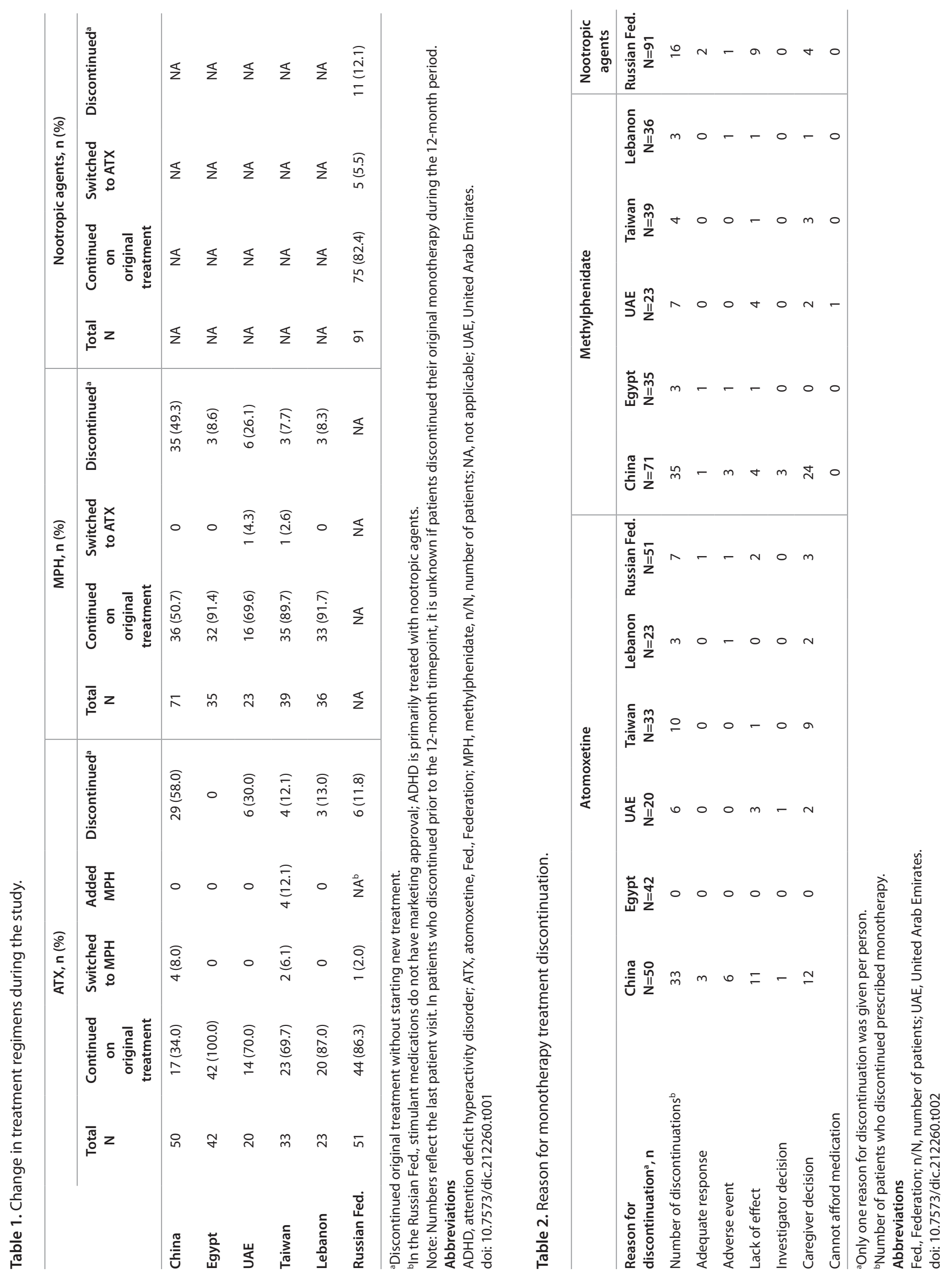
Table 3. Overall patient characteristics.

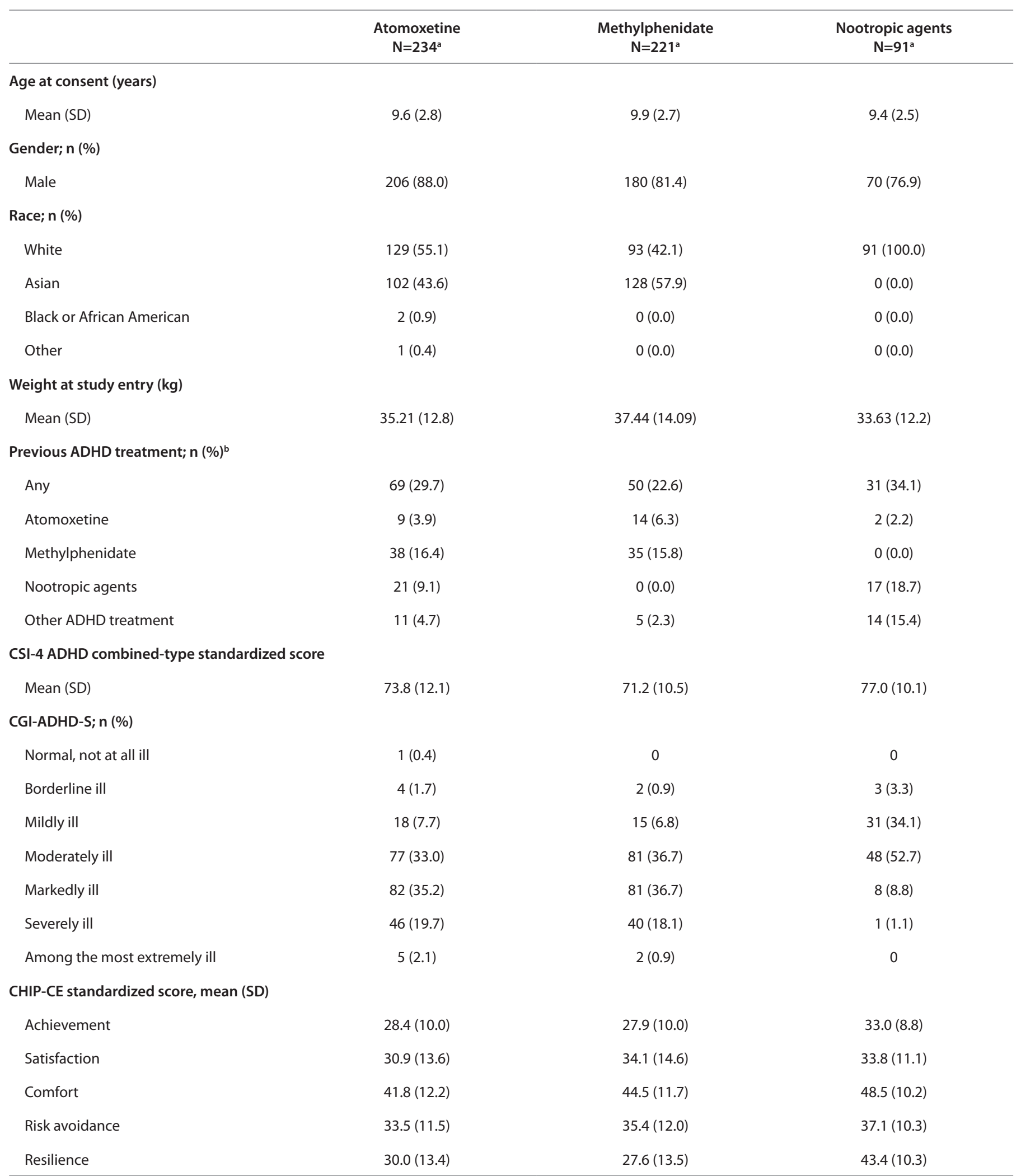

${ }^{a}$ Number of patients per group may vary.

bPatients can be counted in more than 1 category.

Abbreviations

ADHD, attention deficit hyperactivity disorder; CGI-ADHD-S, Clinical Global Impressions-ADHD-Severity; CHIP-CE, Child Health and IIIness Profile-Child Edition; CSI-4, Child Symptom Inventory4; n/N, number of patients; SD, standard deviation.

doi: $10.7573 /$ dic. 212260. t003 


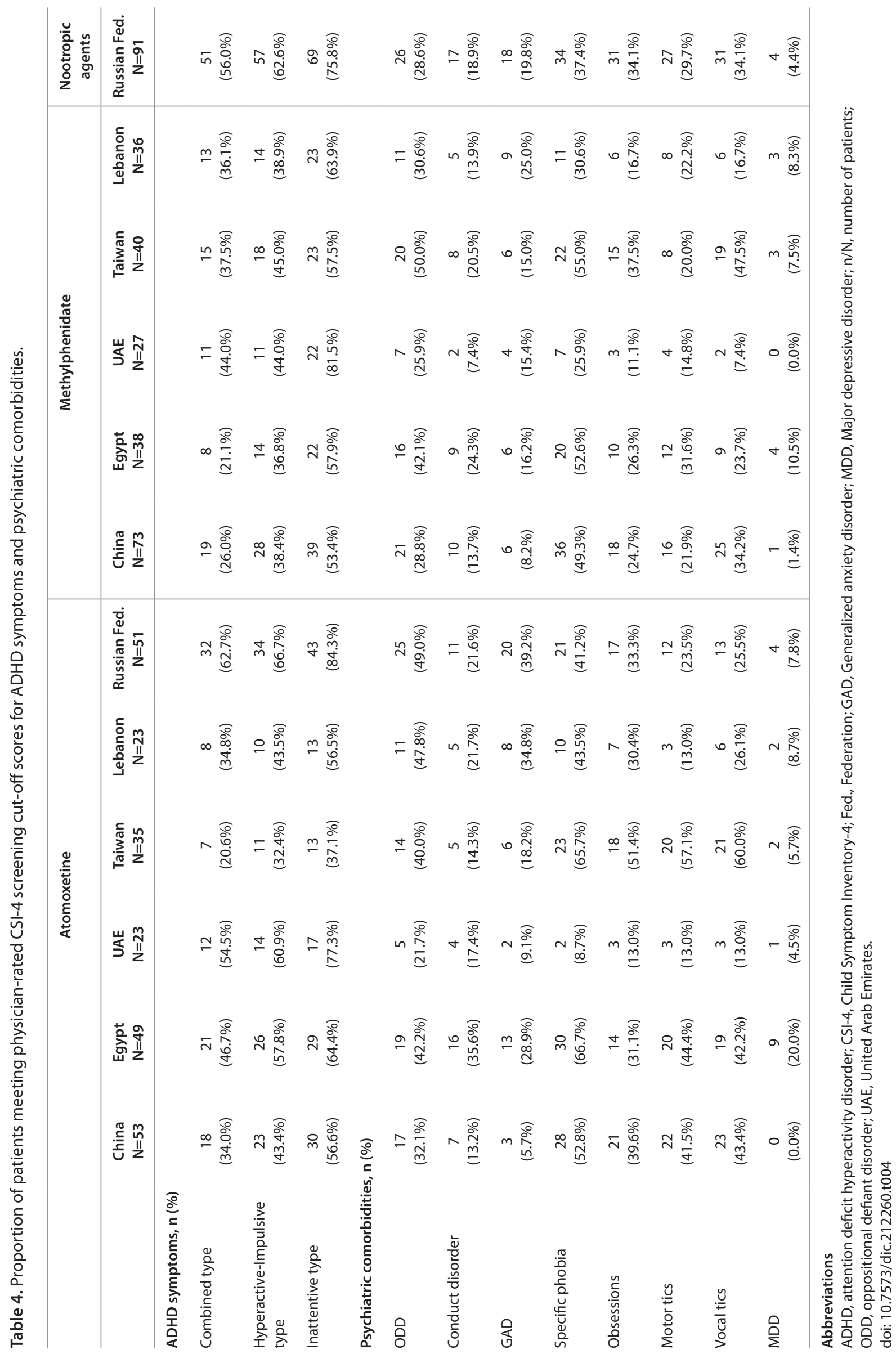


Figure 1a. Mean CHIP-CE achievement domain standardized score.

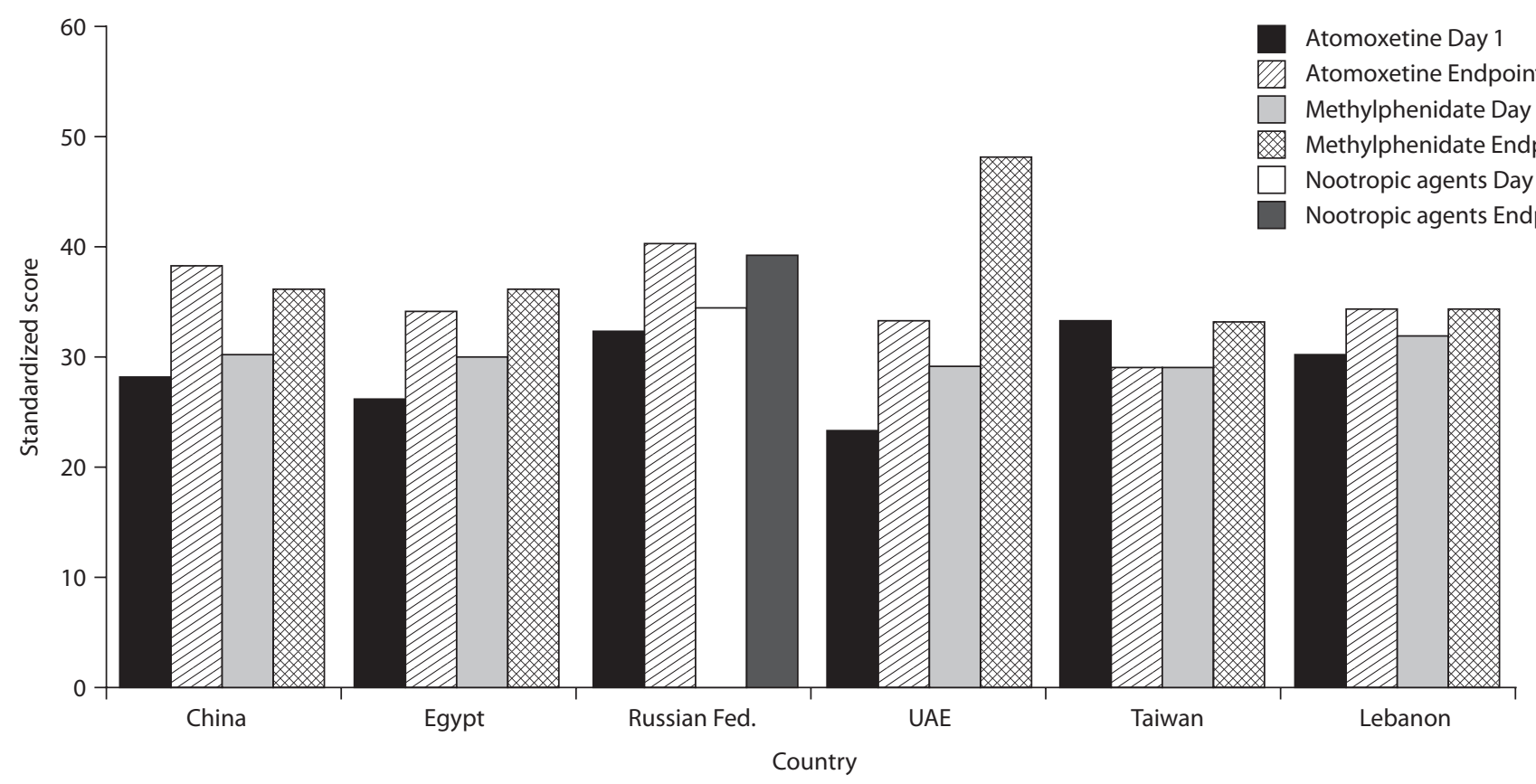

Abbreviations

CHIPCE, Child Health and IIIness Profile-Child Edition; Fed., Federation; UAE, United Arab Emirates. doi: 10.7573/dic.212260.f001a

Figure 1b. Mean CGI-ADHD-S standardized score.

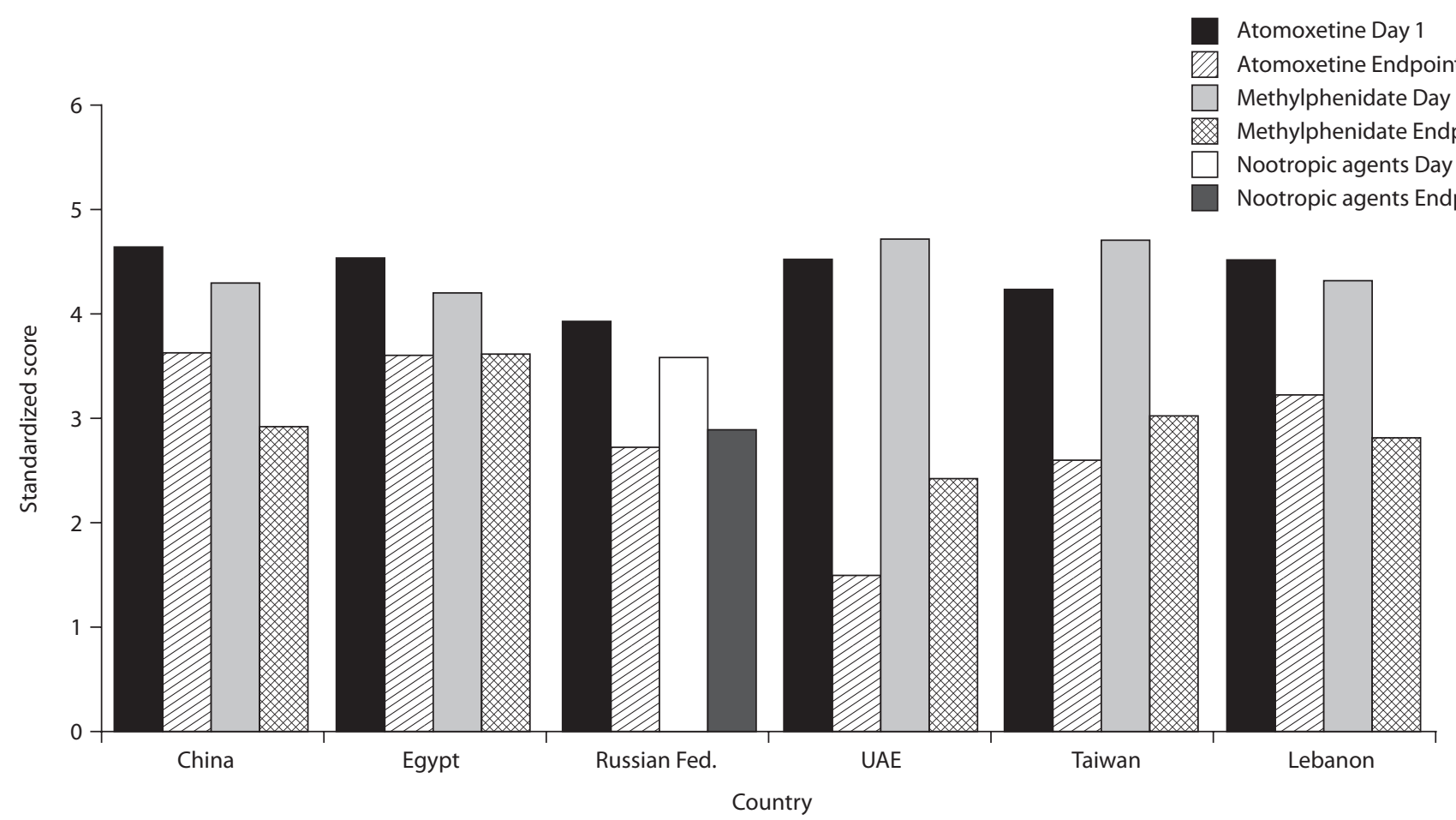

Abbreviations

CHIP-CE, Child Health and IIIness Profile-Child Edition; Fed., Federation; UAE, United Arab Emirates doi: 10.7573/dic.212260.f001b 
atomoxetine $(\mathrm{N}=51)$ and $5.5 \%(\mathrm{n}=5)$ in patients who took nootropic agents $(\mathrm{N}=91)$. The only event to occur in greater than one patient per treatment group was headache (3.9\% [ 2 atomoxetine patients]).

\section{Discussion}

Functional outcomes of ADHD pharmacological treatments may vary in different regions of the world, but there is a critical lack of knowledge regarding treatment of ADHD in many non-Western countries. This study was conducted in six lessstudied non-Western countries, including China, Egypt, the Russian Federation, UAE, Taiwan, and Lebanon. The objective of this study was to describe functional outcomes and their correlation with clinical outcomes and treatment tolerability over a 12-month period in children and adolescents with ADHD, who switch, initiate, or reinitiate treatment. As with studies conducted in other regions, the majority of ADHD patients in this study were male and under the age of 12 [11,17-19,28]. Additionally, most patients were moderately to markedly ill with the exception of patients in the nootropic agents group (in Russia), for which a majority were mild to moderately ill.

The proportion of patients meeting the CSI- 4 cut-off scores for hyperactive-impulsive and inattentive subtypes were different from those previously reported in Western countries, as well as in Eastern Europe and Asia [14,29-31]. Psychiatric comorbidities were common at study entry, which is in agreement with other published reports of comorbidity prevalence rates in patients with ADHD [11,19,32-38]. However, the CSI-4 rating scale does not provide a formal diagnosis and may overestimate the prevalence of comorbidities.

At study entry, CHIP-CE Achievement, Satisfaction, and Risk Avoidance domains indicated an impaired quality of life. After 12 months of treatment, functional and clinical improvements were observed in children and adolescents from non-Western countries who initiated and remained on their prescribed ADHD monotherapy treatment. This was observed with all three therapies evaluated in this study (atomoxetine, methylphenidate, and nootropic agents). On the primary objective, a mean improvement in functional outcomes, as measured by the CHIP-CE Achievement domain score, was observed for patients in all countries and for all therapies at endpoint, with the exception of patients in Taiwan who received atomoxetine and patients in Lebanon who received methylphenidate. The CHIP-CE scores at baseline and the change from baseline were similar to that seen in studies of atomoxetine in children and adolescents in Europe, Canada, and Asia with ADHD [11,19,39]. This study showed a correlation between functional status measured by the Achievement domain and ADHD severity.

With regard to ADHD symptom severity (as measured by the CSI-4 ADHD combined-type score and the CGI-ADHD-S score), improvements at endpoint were observed for patients from all countries and for all therapies, except patients in Taiwan who received atomoxetine; for this subset of patients, improvement in symptom severity was observed on the CGI-ADHD-S but not on the CSI-4 ADHD combined-type score. 
Table 6. Correlation between functional outcome and clinical outcomes.

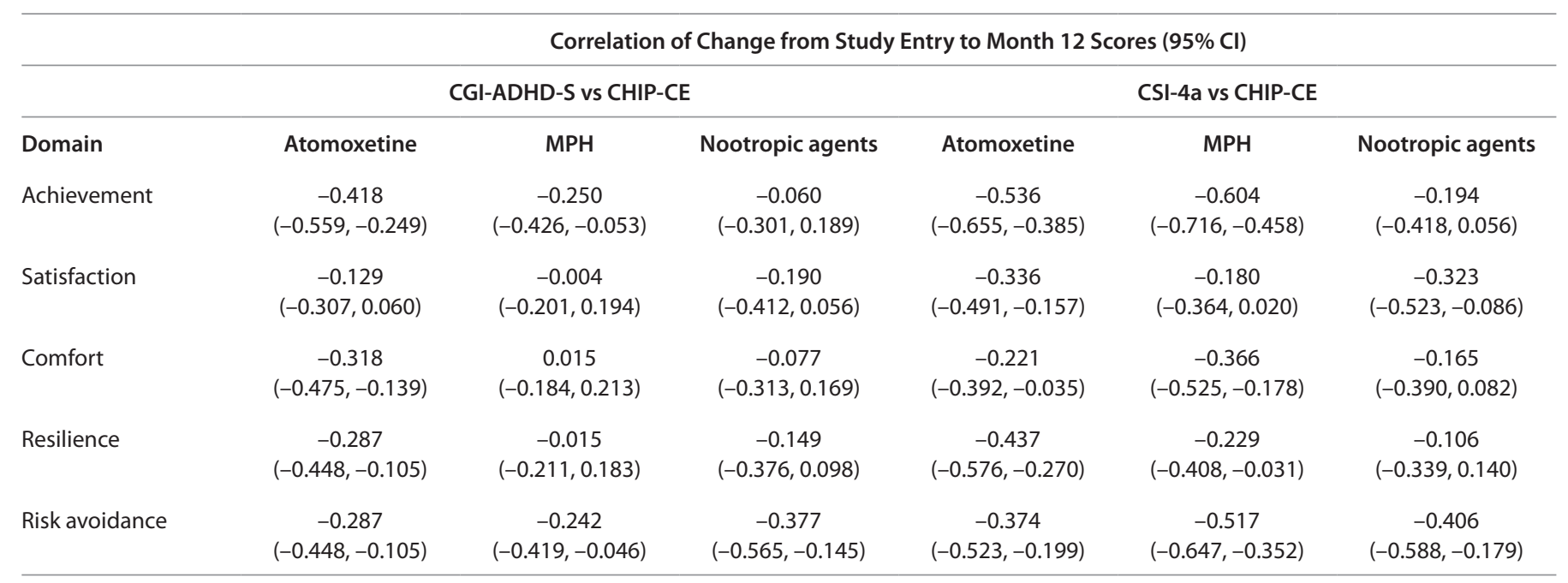

aSymptom severity ADHD Combined-type score.

Abbreviations

ADHD, attention deficit hyperactivity disorder; CGI-ADHD-S, Clinical Global Impressions-ADHD-Severity; CHIP-CE, Child Health and IIIness Profile-Child Edition; $\mathrm{Cl}$, confidence interval; CSI-4, Child Symptom Inventory-4, MPH, methylphenidate.

doi: $10.7573 /$ dic.212260.t006

There are several possible explanations for the difference seen in patients from Taiwan and Lebanon in this study. In Taiwan, atomoxetine is a second-line treatment; patients must first fail methylphenidate before being prescribed atomoxetine. However, the response rates for both atomoxetine and methylphenidate have been shown to be similar and superior to that for placebo [40]. Previous treatment history and ADHD-subtype distribution is different from that in other countries. Study discontinuation was very high for both atomoxetine and methylphenidate. The most common reason for discontinuation was caregiver decision. One could infer from the discontinuations due to caregiver decision that parents had doubts about medical treatment. In addition, a high proportion of atomoxetine-treated patients from Taiwan met screening cut-off scores for obsessions, motor tics, and vocal tics. In Lebanon, patients who received methylphenidate reported lower CHIP-CE Achievement domain scores compared to the scores observed in patients from other countries also receiving methylphenidate. The cause of this difference is unclear.

No new safety outcomes were seen in this study. No patient experienced an SAE during the study, and four patients discontinued due to an AE. The patient tolerability profile differed somewhat between countries, with patients from China having a higher incidence of TEAEs.

Several limitations of our study must be acknowledged. This was a noncomparative, prospective, observational, noninterventional study. While a strength in terms of applicability to the realworld patient population, because of the lack of randomization and blinding, biases including those due to selection are expected. Results presented here are not meant to compare treatments since analyses conducted do not address these biases. In addition, the study was designed to only include patients initiating monotherapy, and so results presented here can only be applied to this population. There were no adjustments done for multiple estimates and low enrollment, and a high discontinuation rate for some countries resulted in lower power to detect meaningful changes. Also, although the CHIP-CE is a well-validated, parent-completed instrument in the United States and Europe $[21,22,41]$, it has not been validated in other countries. These limitations should be taken into account when interpreting the results.

\section{Conclusions}

After 12 months of treatment, functional and clinical improvements were observed, as measured by the CHIP-CE, in children and adolescents from non-Western countries who initiated and remained on their prescribed ADHD monotherapy treatment. In the present study, few ADHD monotherapy treatment patients discontinued due to AEs over the 12-month trial, which shows that atomoxetine, methylphenidate, and nootropic agents were well tolerated in patients from these regions.

\section{Funding declaration and acknowledgments}

The original trial was funded by, and sponsored by Eli Lilly and Company and/or any of its subsidiaries, Indianapolis, IN. We would like to thank inVentiv Health Clinical, LLC, for their help with writing, editing, and formatting. We would like to thank Anna Ershova, MD, for her conceptual help.

\section{References}

1. American Psychiatric Association. Diagnostic and Statistical Manual of Mental Disorders, 4th ed., Text Revision (DSM- 
IV-TR): Washington, DC; American Psychiatric Association, 2000.

2. Wolraich M, Brown L, Brown RT, et al. ADHD: clinical practice guideline for the diagnosis, evaluation, and treatment of attention-deficit/hyperactivity disorder in children and adolescents. Pediatrics 2011;128:1007-22. http:// dx.doi.org/10.1542/peds.2011-2654

3. Froehlich TE, McGough JJ, Stein MA. Progress and promise of attention-deficit hyperactivity disorder pharmacogenetics. CNS Drugs 2010;24:99-117. http://dx.doi. org/10.2165/11530290-000000000-00000

4. Sonuga-Barke E, Bitsakou P, Thompson M. Beyond the dual pathway model: evidence for the dissociation of timing, inhibitory, and delay-related impairments in attentiondeficit/hyperactivity disorder. J Am Acad Child Adolesc Psychiatry 2010;49:345-55. http://dx.doi.org/10.1016/j. jaac.2009.12.018

5. Faraone SV, Biederman J, Mick E, et al. A family study of psychiatric comorbidity in girls and boys with attention-deficit/hyperactivity disorder. Biol Psychiatry 2001;50:586-92.

6. Pastor PN, Reuben CA. Attention Deficit Disorder and Learning Disability: United States, 1997-98. Vital Health Stat 10. 2002;1-12.

7. Bagwell CL, Molina BS, Pelham WE, Jr., Hoza B. Attention-deficit hyperactivity disorder and problems in peer relations: predictions from childhood to adolescence. J Am Acad Child Adolesc Psychiatry 2001;40:1285-92. http://dx.doi. org/10.1097/00004583-200111000-00008

8. Greene RW, Biederman J, Faraone SV, et al. Social impairment in girls with ADHD: patterns, gender comparisons, and correlates. J Am Acad Child Adolesc Psychiatry 2001;40:704-10. http://dx.doi.org/10.1097/00004583-200106000-00016

9. Thurber JR, Heller TL, Hinshaw SP. The social behaviors and peer expectation of girls with attention deficit hyperactivity disorder and comparison girls. J Clin Child Adolesc Psychol 2002;31:443-52. http://dx.doi.org/10.1207/S15374424JCCP3104 4

10. Seixas M, Weiss M, Muller U. Systematic review of national and international guidelines on attention-deficit hyperactivity disorder. J Psychopharmacol 2012;26:753-65. http:// dx.doi.org/10.1177/0269881111412095

11. Martenyi F, Treuer T, Gau SS, et al. Attention-deficit/hyperactivity disorder diagnosis, co-morbidities, treatment patterns, and quality of life in a pediatric population in central and eastern Europe and Asia. J Child Adolesc Psychopharmacol 2009;19:363-76. http://dx.doi.org/10.1089/cap.2008.0148

12. Zavadenko NN, Suvorinova SI. [Therapeutic efficacy of nootropil different doses in attention deficit hyperactivity disorder]. Zh Nevrol Psikhiatr Im S S Korsakova 2004;104:327.

13. Zavadenko NN, Suvorinova NI. [Attention-deficit hyperactivity disorder: determination of the optimal medical treatment duration]. Zh Nevrol Psikhiatr Im S S Korsakova 2011;111:28-32.

14. Martenyi F, Zavadenko NN, Jarkova NB et al. Atomoxetine in children and adolescents with attention-deficit/hyperactivity disorder: a 6-week, randomized, placebo-controlled, double- blind trial in Russia. Eur Child Adolesc Psychiatry 2010;19:5766. http://dx.doi.org/10.1007/s00787-009-0042-7

15. Bymaster FP, Katner JS, Nelson DL, et al. Atomoxetine increases extracellular levels of norepinephrine and dopamine in prefrontal cortex of rat: a potential mechanism for efficacy in attention deficit/hyperactivity disorder. Neuropsychopharmacology 2002;27:699-711. http://dx.doi.org/10.1016/ S0893-133X(02)00346-9

16. Michelson D, Faries D, Wernicke J, et al. Atomoxetine in the treatment of children and adolescents with attention-deficit/ hyperactivity disorder: a randomized, placebo-controlled, dose-response study. Pediatrics 2001;108:E83. http://dx.doi. org/10.1542/peds.108.5.e83

17. Michelson D, Allen AJ, Busner J, et al. Once-daily atomoxetine treatment for children and adolescents with attention deficit hyperactivity disorder: a randomized, placebo-controlled study. Am J Psychiatry 2002;159:1896-901. http:// dx.doi.org/10.1176/appi.ajp.159.11.1896

18. Spencer T, Biederman J, Heiligenstein J, et al. An openlabel, dose-ranging study of atomoxetine in children with attention deficit hyperactivity disorder. J Child Adolesc Psychopharmacol 2001;11:251-65. http://dx.doi. org/10.1089/10445460152595577

19. Prasad S, Harpin V, Poole L, et al. A multi-centre, randomised, open-label study of atomoxetine compared with standard current therapy in UK children and adolescents with attention-deficit/hyperactivity disorder (ADHD). Curr Med Res Opin 2007;23:379-94. http://dx.doi. org/10.1185/030079906X167309

20. Ralston SJ, Lorenzo MJ. ADORE - Attention-Deficit Hyperactivity Disorder Observational Research in Europe. Eur Child Adolesc Psychiatry 2004;13 Suppl 1:I36-I42. http:// dx.doi.org/10.1007/s00787-004-1004-8

21. Riley AW, Coghill D, Forrest CB, et al. Validity of the healthrelated quality of life assessment in the ADORE study: Parent Report Form of the CHIP-Child Edition. Eur Child Adolesc Psychiatry 2006;15 Suppl 1:I63-I71. http://dx.doi. org/10.1007/s00787-006-1009-6

22. Riley AW, Forrest CB, Rebok GW, et al. The Child Report Form of the CHIP-Child Edition: reliability and validity. Med Care 2004;42:221-31. http://dx.doi.org/10.1097/01. mlr.0000114910.46921.73

23. Riley AW, Forrest CB, Starfield B, et al. The Parent Report Form of the CHIP-Child Edition: reliability and validity. Med Care 2004;42:210-20. http://dx.doi.org/10.1097/01. mlr.0000114909.33878.ca

24. Guy W. ECDEU Assessment Manual for Psychopharmacology, Revised. Bethesda, MD: US Department of Health, Education and Welfare, 1976.

25. Gadow KD, Sprafkin J. Child Symptom Inventory - 4: Screening and Norms Manual. Stony Brook, NY: Checkmate Plus, 2002.

26. Gadow KD, Sprafkin J. Adolescent Symptom Inventory - 4: Norms Manual. Stony Brook, NY: Checkmate Plus, 1998.

27. Johns Hopkins University. Child Health and Illness Profile (CHIP). Available at: http://www.childhealthprofile.org [Last accessed 13 September 2013]. 
28. Kelsey DK, Sumner CR, Casat CD, et al. Once-daily atomoxetine treatment for children with attention-deficit/ hyperactivity disorder, including an assessment of evening and morning behavior: a double-blind, placebo-controlled trial. Pediatrics 2004;114:e1-e8. http://dx.doi.org/10.1542/ peds.114.1.e1

29. Goetz M, Yeh CB, Ondrejka I, et al. A 12-month prospective, observational study of treatment regimen and quality of life associated with ADHD in central and eastern europe and eastern Asia. J Atten Disord 2012;16:44-59. http://dx.doi. org/10.1177/1087054710381480

30. Martenyi F, Zheng Y, Huang YS, et al. A prospective observational study of attention-deficit hyperactivity disorder in Asia: baseline characteristics of symptom severity and treatment options in a paediatric population. East Asian Arch Psychiatry 2010;20:76-86.

31. Ondrejka I, Abali O, Paclt I, et al. A prospective, observational study of attention-deficit /hyperactivity disorder in central and eastern Europe and Turkey: symptom severity and treatment options in a paediatric population. Int J Psychiat Clin 2010;14:116-26. http://dx.doi. org/10.3109/13651500903556511

32. Bangs ME, Hazell P, Danckaerts M, et al. Atomoxetine for the treatment of attention-deficit/hyperactivity disorder and oppositional defiant disorder. Pediatrics 2008;121:e314e320. http://dx.doi.org/10.1542/peds.2006-1880

33. Elia J, Ambrosini P, Berrettini W. ADHD characteristics: I. Concurrent co-morbidity patterns in children $\&$ adolescents. Child Adolesc Psychiatry Ment Health 2008;2:15. http:// dx.doi.org/10.1186/1753-2000-2-15

34. Erol N, Simsek Z, Oner O, Munir K. Epidemiology of attention problems among Turkish children and adolescents: a national study. J Atten Disord 2008;11:538-45. http://dx.doi. org/10.1177/1087054707311214

35. Ersan EE, Dogan O, Dogan S, Sumer H. The distribution of symptoms of attention-deficit/hyperactivity disorder and oppositional defiant disorder in school age children in Turkey. Eur Child Adolesc Psychiatry 2004;13:354-61. http:// dx.doi.org/10.1007/s00787-004-0410-2

36. Goldman LS, Genel M, Bezman RJ, Slanetz PJ. Diagnosis and treatment of attention-deficit/hyperactivity disorder in children and adolescents. Council on Scientific Affairs, American Medical Association. JAMA 1998;279:1100-7. http://dx.doi.org/10.1001/jama.279.14.1100

37. Nolan EE, Gadow KD, Sprafkin J. Teacher reports of DSMIV ADHD, ODD, and CD symptoms in schoolchildren. J Am Acad Child Adolesc Psychiatry 2001;40:241-9. http:// dx.doi.org/10.1097/00004583-200102000-00020

38. The MTA Cooperative Group. A 14-month randomized clinical trial of treatment strategies for attention-deficit/hyperactivity disorder. The MTA Cooperative Group. Multimodal Treatment Study of Children with ADHD. Arch Gen Psychiatry 1999;56:1073-86. http://dx.doi.org/10.1001/ archpsyc.56.12.1073

39. Wehmeier PM, Schacht A, Escobar R, Savill N, Harpin V. Differences between children and adolescents in treatment response to atomoxetine and the correlation between healthrelated quality of life and Attention Deficit/Hyperactivity Disorder core symptoms: Meta-analysis of five atomoxetine trials. Child Adolesc Psychiatry Ment Health 2010;4:30. http://dx.doi.org/10.1186/1753-2000-4-30

40. Newcorn JH, Kratochvil CJ, Allen AJ, et al. Atomoxetine and osmotically released methylphenidate for the treatment of attention deficit hyperactivity disorder: acute comparison and differential response. Am J Psychiatry 2008;165:721-30. http://dx.doi.org/10.1176/appi.ajp.2007.05091676

41. Riley AW, Forrest CB, Starfield B, Rebok GW, Robertson JA, Green BF. The Parent Report Form of the CHIP-Child Edition: reliability and validity. Med Care 2004;42:210-20. http://dx.doi.org/10.1097/01.mlr.0000114909.33878.ca 